\title{
Appliance of the ICH Guidelines: Forced Degradation Studies on Abafungin and Development of Validated Stability Indicating Method by $1^{\text {st }}$ Order Derivative Spectroscopy
}

\author{
Swati Pandey', Ravindra Pandey², Shiv Shankar Shukla ${ }^{1, *}$ \\ 1Department of Pharmaceutical Analysis and Quality Assurance, Columbia Institute of Pharmacy, Raipur, Chhattisgarh, INDIA. \\ ${ }^{2}$ Department of Pharmacognosy, Columbia Institute of Pharmacy, Raipur, Chhattisgarh, INDIA.
}

\begin{abstract}
Background: The presented study is a stability indicating simple, precise and accurate $1^{\text {st }}$ order UV derivative spectroscopic method that is being studied under the different stated International Council for Harmonization (ICH) Guidelines for the forced degradation and establishes a validated method for Abafungin and its main degradants in the active pharmaceutical ingredients (API) and the marketed formulations. Materials and Methods: Adhering to the $\mathrm{ICH}$ guidelines the analytical parameters viz. linearity, range, precision, recovery, robustness and ruggedness were validated. The method was based on thorough stress testing with acid, base, thermal, photolytic and oxidative degradations. Results: It was found that a linear response is present in the concentration range of $5-50 \mu \mathrm{g} / \mathrm{mL}$ at $242 \mathrm{~nm}$. The \% relative standard deviation (RSD) for precision studies of Intraday and Interday were $<1.2 \%$ and $<1.9 \%$ respectively. Conclusion: The appropriateness of the developed method was tested by analyzing the marketed cream of Abafungin and the thorough forced degradations studies was able to predict the stability of Abafungin in the marketed formulation. The method is found to be unambiguous to both the drug and its degradants.
\end{abstract}

Key words: Abafungin, Forced degradation studies, $1^{\text {st }}$ order derivative UV spectroscopy, Method development and validation, Stress testing.

\section{INTRODUCTION}

Stability indicating method (SIM) establishes such a developed and validated method where the drug substance and the marketed formulation can be identified along with the degradants unambiguously in a dosage form. The ICH Q2 (R1) guideline depicts the development of a method and the validation parameters ${ }^{1}$ and on the parallel hands is the ICH Q3 A, Q3B and Q3C guidelines that support the identification and the characterization of the impurities and its degradation product in the active pharmaceutical ingredients (API), drug products and residual solvents. ${ }^{2-4}$ Exposing the drug Substances to thermal degradation, $\mathrm{pH}$ degradation, alkaline and acid hydrolysis, photolytic and acidic degradation may lead to the development of degradants that needs to be identified and characterized if the above the threshold limits as the further development of these degradants may lead to genotoxicity. ${ }^{5,6}$

The need of the hour is the development of such a method where the impurities and the degradants can be simultaneously estimated in a method.SIM is such a method where the compound is subjected to stress conditions that are severe to the accelerated Stability studies as stated in the ICH Q1A guideline. ${ }^{7-11}$ In the present study a topical antimycotic abafungin (Figure 1), N-\{4-[2(2, 4-dimethylphenoxy) phenyl]-1, 3-thiazol2-yl\}-1,4,5,6-tetrahydro-2-pyrimidinamine,
Submission Date: 03-07-2020; Revision Date: 02-12-2020; Accepted Date: 20-01-2021

DOI: 10.5530/ijper.55.1.28 Correspondence: Dr. Shiv Shankar Shukla Professor, Department of Pharmaceutical Analysis and Quality Assurance, Columbia Institute of Pharmacy, Raipur, Chhattisgarh, INDIA. Phone: +91 9826124442 E-mail: shivpharma007@ gmail.com

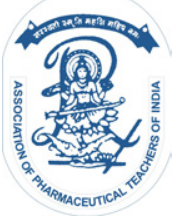

www.ijper.org 
which is the first representative of a new class of drugs with the name arylguanidines has been selected for the study. Abafungin has a broad spectrum of action against dermatophytes, yeasts and moulds. ${ }^{12,13}$ Abafungin inhibits the ergosterol synthesis and also helpful indirectly damaging the fungal membrane. It competitively inhibits S-adenosylmethionine (SAM) dependent 24-sterol methyltransferase (24-SMT). ${ }^{12}$ As reported by the clinical studies on the investigation of the efficacy of abafungin in the treatment of fungal infection by Candida species have reported that abafungin shows a sufficient efficacy and has a broad spectrum of action. ${ }^{14,15}$

Development of a method for abafungin has not been yet reported as because the solubility of the drug is very rare in the commonly available solvents. Thereby it's needed to develop a rapid, simple, reproducible and economical method for the routine analysis of abafungin in its pure and solid/liquid dosage form. The proposed method used diethylene glycol mono ether (Transcutol) as a potential solvent for the estimation of the drug in bulk and dosage form. The present work describes a stability-indicating method for the estimation of abafungin.

\section{Experimental}

Abafungin was procured from as a gift sample Aurobindo Pharmaceuticals, Aurangabad that was further tested for purity by testing the melting pint and recording the FTIR spectrum. Pharmaceutical preparations of abafungin (Abasol, York Pharma) were obtained from local pharmacies. Diethylene glycol mono ether (Transcutol) from Qualigens Fine chemicals, Mumbai. Shimadzu 1800 model UV-VIS spectrophotometer was the spectrometric instrument. Analytical grade chemicals and double distilled water was used for the study each time.

\section{Standard solution of abafungin}

Accurately weighed Abafungin (25 mg) was transferred to a $25 \mathrm{~mL}$ volumetric flask, dissolved in diethylene glycol mono ether and filtered. Then the filtered solution was diluted up to the mark with diethylene glycol mono ether. Here the concentration achieved was $1000 \mu \mathrm{g} /$ $\mathrm{mL}$. After further diluting $1 \mathrm{~mL}$ of the solution with 10 $\mathrm{mL}$ of same solvent the final concentration of $100 \mu \mathrm{g} /$ $\mathrm{mL}$ was obtained that was denoted as the working stock solution.

\section{Selection of detection wavelength and construction of the calibration curve}

To attain the spectrometric analysis of abafungin solution, initially, the solvent blank was recorded at 200 $\mathrm{nm}$ to $400 \mathrm{~nm}$ with the solvent diethylene glycol mono ether. An absorbance maximum was selected as 242.0 $\mathrm{nm}$ for the entire recorded spectrum. The working stock solution was utilized to prepare the various aliquots ranging from $5 \mu \mathrm{g} / \mathrm{mL}$ to $50 \mu \mathrm{g} / \mathrm{mL}$. Absorbance recorded for all the aliquots at $242 \mathrm{~nm}$ was plotted as the calibration curve (Figure 2 and 3).

\section{Analytical method development and validation}

The proposed method was developed and validated with respect to the ICH Q2 guidelines parameters linearity, range, accuracy, precision, LOD, LOQ, sensitivity and forced degradation study. Selected detection wavelength $242 \mathrm{~nm}$ corresponds to less interference of related substances and shows suitable absorption.

\section{Linearity and Range}

The proposed method shows linearity in the range of 5 to $50 \mu \mathrm{g} / \mathrm{mL}$ with 9 different aliquots $(n=6)$. The correlation coefficient $R^{2}$ was found to be 0.998 with the regression equation $y=0.002 x+0.008$ where 0.002 is the slope and 0.008 is the intercept.

\section{Limit of detection (LOD) and Limit of quantification (LOQ)}

The LOD and LOQ values of Abafungin were from the regression equation. Applying the formula, LOD and LOQ were found to be $0.505 \mu \mathrm{g}$ and $1.53 \mu \mathrm{g}$ respectively (Table 1).

LOD $=3.3 \times$ Standard deviation of intercept/Mean of slope

LOQ $=10 \times$ Standard deviation of intercept/Mean of slope

\section{Precision}

To determine how precise a method is the repeatability of the results are studied within a short interval of time. Interday precision study was performed on a single day at different time (regular interval). For intraday precision

\begin{tabular}{|c|c|c|}
\hline S. No. & Validation criteria & Result \\
\hline 1 & $\begin{array}{c}\text { Absorbance Maxima/Detection } \\
\text { Wavelength }\end{array}$ & $242 \mathrm{~nm}$ \\
\hline 2 & Linearity Response & $5-50 \mu \mathrm{g} / \mathrm{mL}$ \\
\hline 3 & Beer's law limits & $5-50 \mu \mathrm{g} / \mathrm{mL}$ \\
\hline 4 & Slope & 0.002 \\
\hline 5 & Intercept & 0.008 \\
\hline 6 & Regression equation & $y=0.002 x+0.008$ \\
\hline 7 & LOD & $0.505 \mu \mathrm{g}$ \\
\hline 8 & LOQ & $1.53 \mu g$ \\
\hline
\end{tabular}


study, same concentration was analyzed for consecutive days in a week at the similar time (Table 2).

\section{Robustness}

6 aliquots form the slot was analyzed by different analyst using different pipettes and at different temperature to determine the robustness of the method (Table 2).

\section{Sandell's Sensitivity}

In spectrophotometry, Sandell's Sensitivity $(\Lambda)$ is the term assigned for determining the sensitivity. It denotes the capacity of the method to analyze small variation in concentration (Table 2).

Sandell's Sensitivity $\Lambda=$ Concentration of drug in $\mu \mathrm{g} / 100 \mathrm{~mL}$ x $0.001 /$ Absorbance

\section{Accuracy/ Recovery Studies}

As per the Indian Pharmacopoeia the accuracy was determined at three different levels of 50,100 and $150 \%$. This denotes the closeness of reference and the calculated value. A known amount of standard solution

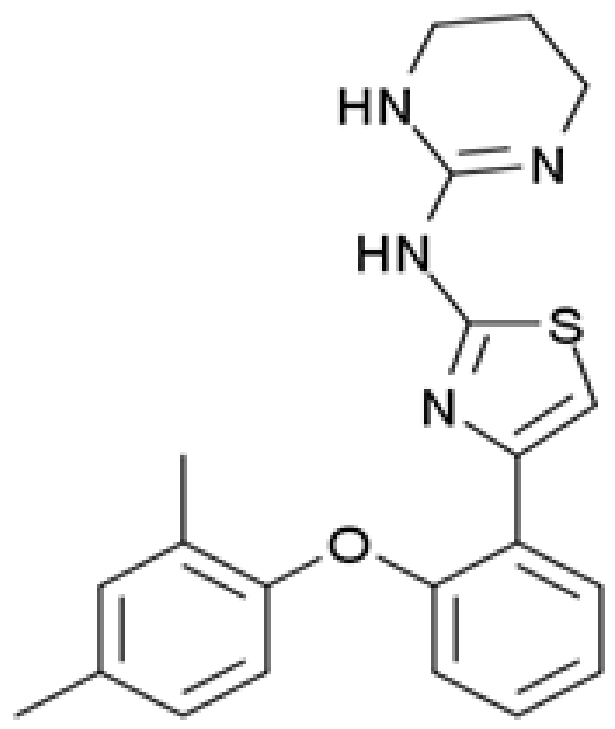

Figure 1: Structure of Abafungin.

\begin{tabular}{|c|c|c|}
\hline \multicolumn{3}{|c|}{ Table 2: Results of the different validated analytical } \\
parameters
\end{tabular}

of drug was added to the different levels of drug solution from the dosage form. The proposed method was used to analyze the resultant solutions (Table 3).

\section{Degradation studies of Abafungin pH Degradation studies}

To study the effect of $\mathrm{pH}$ on the drug $0.1 \mathrm{~N}$ and $2 \mathrm{~N}$ hydrochloric acid and $0.1 \mathrm{~N}$ and $2 \mathrm{~N}$ sodium hydroxide solution was used to achieve the $\mathrm{pH}$ range from 0-14. The sample under study was kept undisturbed for 4 hr. After $4 \mathrm{hr}$ the absorbance was recorded at $242 \mathrm{~nm}$ (Table 4).

To determine the $\mathrm{K}$ value of $1^{\text {st }}$ order kinetics equation is: $\mathrm{K}=(2.303 / \mathrm{t}) \log \left(\mathrm{C}_{\mathrm{o}} / \mathrm{C}\right)$

Where, $\mathrm{K}$ is $1^{\text {st }}$ order rate constant, $\mathrm{C}_{\mathrm{o}}$ is the initial drug concentration and $\mathrm{C}$ is the final drug concentration.

\section{Stress degradation by acidic hydrolysis}

To $3 \mathrm{~mL}$ of stock solution $(1 \mathrm{mg} / \mathrm{mL})$ of abafungin $1 \mathrm{ml}$ of $3 \mathrm{~N} \mathrm{HCl}$ was added and volume made up to 10 $\mathrm{mL}$ by using transcutol and kept at normal conditions undisturbed for $90 \mathrm{~min}$. After $15 \mathrm{~min}, 1 \mathrm{~mL}$ was pipette

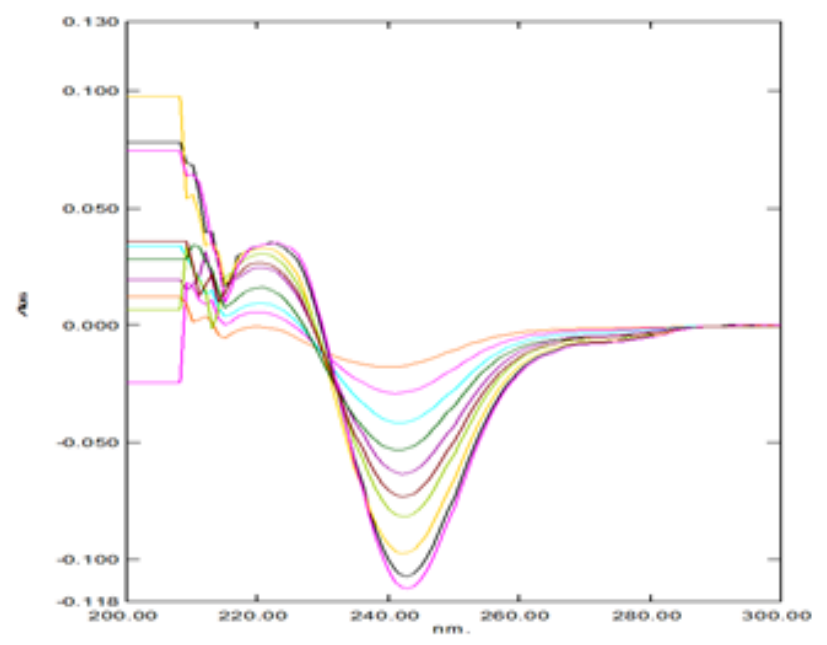

Figure 2: Overlay spectrum of abafungin $(5-50 \mu \mathrm{g} / \mathrm{mL})$.

\begin{tabular}{|c|c|c|c|c|}
\hline \multicolumn{5}{|c|}{ Table 3: Result of Recovery studies by $1^{\text {st }}$ Order } \\
Derivative Spectroscopy \\
$\begin{array}{c}\text { Level of } \\
\text { Recovery }\end{array}$ & $\begin{array}{c}\text { Amount } \\
\text { of } \\
\text { Standard }\end{array}$ & $\begin{array}{c}\text { Amount } \\
\text { of Sample }\end{array}$ & $\begin{array}{c}\text { Amount } \\
\text { Recovered }\end{array}$ & $\begin{array}{c}\% \\
\text { Recovery }\end{array}$ \\
\hline $50 \%$ & 30 & 15 & 32.28 & $107.6 \%$ \\
\hline $100 \%$ & 30 & 30 & 32 & $100.66 \%$ \\
\hline $150 \%$ & 30 & 45 & 30.5 & $101.66 \%$ \\
\hline
\end{tabular}




\begin{tabular}{|c|c|c|c|c|c|}
\hline \multicolumn{5}{|c|}{ Table 4: pH Degradation Results } \\
\hline pH & $\begin{array}{c}\text { D1 } \\
\text { Value }\end{array}$ & $\begin{array}{c}\text { Conc }(\mu \mathrm{g} / \\
\mathbf{m L})\end{array}$ & $\begin{array}{c}\text { \% Drug } \\
\text { degraded }\end{array}$ & K Value & Log K \\
\hline 0 & 0.048 & 18.113 & 9.434 & 0.0247 & -1.6073 \\
\hline 1 & 0.049 & 18.490 & 7.547 & 0.0196 & -1.70774 \\
\hline 2 & 0.055 & 20.755 & 3.773 & 0.0093 & -2.03152 \\
\hline 3 & 0.055 & 20.754 & 3.773 & 0.0093 & -2.03152 \\
\hline 4 & 0.054 & 20.377 & 1.886 & 0.0047 & -2.3279 \\
\hline 5 & 0.054 & 20.377 & 1.886 & 0.0047 & -2.3279 \\
\hline 6 & 0.053 & 20.075 & 0.377 & 0.0009 & -3.04576 \\
\hline 7 & 0.053 & 20.188 & 0.943 & 0.0024 & -2.61979 \\
\hline 8 & 0.055 & 20.754 & 3.773 & 0.0093 & -2.03152 \\
\hline 9 & 0.056 & 21.132 & 5.660 & 0.0137 & -1.86328 \\
\hline 10 & 0.057 & 21.509 & 7.547 & 0.0182 & -1.73993 \\
\hline 11 & 0.058 & 21.886 & 9.433 & 0.0225 & -1.64782 \\
\hline 12 & 0.058 & 21.886 & 9.433 & 0.0225 & -1.64782 \\
\hline 13 & 0.059 & 22.264 & 11.320 & 0.0268 & -1.57187 \\
\hline 14 & 0.061 & 23.018 & 15.0943 & 0.0352 & -1.45346 \\
\hline & & & & & \\
\hline
\end{tabular}

out and diluted further with transcutol to achieve a concentration of $30 \mu \mathrm{g} / \mathrm{mL}$.

For blank, $0.5 \mathrm{~mL}$ solution of $3 \mathrm{~N} \mathrm{HCl}$ and $0.5 \mathrm{~mL}$ solution of $3 \mathrm{~N} \mathrm{NaOH}$ were diluted with transcutol in 10 $\mathrm{mL}$ volumetric flask. After $15 \mathrm{~min}, 1 \mathrm{~mL}$ of the solution was pipetted from the flask and the same procedure was performed (Table 5).

\section{Stress degradation by alkaline hydrolysis}

To $3 \mathrm{~mL}$ of stock solution, $1 \mathrm{~mL}$ of $1 \mathrm{~N} \mathrm{NaOH}$ was added and volume made up to the mark with transcutol. The volumetric was kept undisturbed for 90 min. After $15 \mathrm{~min}, 1 \mathrm{~mL}$ of the solution was pipette, neutralized and diluted with transcutol up to $10 \mathrm{~mL}$ and further dilutions were carried out to achieve $30 \mu \mathrm{g} / \mathrm{mL}$. Blank was also prepared similarly.

\section{Dry heat-induced Degradation}

Abafungin was taken in a petri-plate and exposed to a temperature of $70^{\circ} \mathrm{C}$ for $48 \mathrm{hr}$ in an oven. Further dilution was prepared to achieve $30 \mu \mathrm{g} / \mathrm{mL}$ concentrations and analyzed (Table 5).

\section{Oxidative Degradation}

To $1.5 \mathrm{~mL}$ of $1 \mathrm{mg} / \mathrm{mL}$ of abafungin, $1 \mathrm{~mL}$ of $30 \%$ $\mathrm{w} / \mathrm{v}$ of hydrogen peroxide was added and volume made up to $10 \mathrm{~mL}$ with transcutol. The sample was kept for $15 \mathrm{~min}$ at room temperature. For blank, $1 \mathrm{~mL}$ of $30 \%$ w/v hydrogen peroxide dilute with transcutol up to 10

\section{Table 5: Results of stress degradation study}

\begin{tabular}{|c|c|c|c|}
\hline S. No & Condition & Time & $\begin{array}{c}\% \\
\text { degradation }\end{array}$ \\
\hline \multirow{2}{*}{1.} & \multirow{2}{*}{$\begin{array}{c}\text { Acidic }\{(3 \mathrm{~N} \mathrm{HCl}) 1 \mathrm{ml}\} \\
\mathrm{API}\end{array}$} & $60 \mathrm{~min}$ & $13.72 \%$ \\
\hline & & $90 \mathrm{~min}$ & $20.44 \%$ \\
\hline \multirow{2}{*}{2.} & \multirow{2}{*}{$\begin{array}{l}\text { Acidic }\{(3 \mathrm{~N} \mathrm{HCl}) 1 \mathrm{ml}\} \\
\text { Formulation }\end{array}$} & $60 \mathrm{~min}$ & $14.55 \%$ \\
\hline & & $90 \mathrm{~min}$ & $19.56 \%$ \\
\hline \multirow{2}{*}{3.} & \multirow{2}{*}{$\begin{array}{c}\text { Alkaline }\{0.1 \mathrm{~N} \mathrm{NaOH} \\
(1 \mathrm{ml})\} \mathrm{API}\end{array}$} & $60 \mathrm{~min}$ & $7.57 \%$ \\
\hline & & $90 \mathrm{~min}$ & $9.63 \%$ \\
\hline \multirow{2}{*}{4.} & \multirow{2}{*}{$\begin{array}{l}\text { Alkaline }\{0.1 \mathrm{~N} \mathrm{NaOH} \\
(1 \mathrm{ml})\} \text { Formulation }\end{array}$} & $60 \mathrm{~min}$ & $8.53 \%$ \\
\hline & & $90 \mathrm{~min}$ & $10.69 \%$ \\
\hline 5. & $\begin{array}{c}\text { Oxidative }\{30 \% \\
\text { Hydrogen } \\
\text { Peroxide }(1 \mathrm{ml})\} \text { API }\end{array}$ & $15 \min$ & $24.65 \%$ \\
\hline 6. & $\begin{array}{l}\text { Oxidative }\{30 \% \\
\text { Hydrogen } \\
\text { Peroxide }(1 \mathrm{ml})\} \\
\text { Formulation }\end{array}$ & $15 \mathrm{~min}$ & $23.85 \%$ \\
\hline 7. & Dry heat $70^{\circ} \mathrm{C} \mathrm{API}$ & $48 \mathrm{hr}$ & $5.36 \%$ \\
\hline 8. & $\begin{array}{c}\text { Dry heat } 70^{\circ} \mathrm{C} \\
\text { Formulation }\end{array}$ & $48 \mathrm{hr}$ & $6.32 \%$ \\
\hline 9. & Photolytic API & $154 \mathrm{hr}$ & $1.36 \%$ \\
\hline 10. & Photolytic Formulation & $154 \mathrm{hr}$ & $1.69 \%$ \\
\hline
\end{tabular}

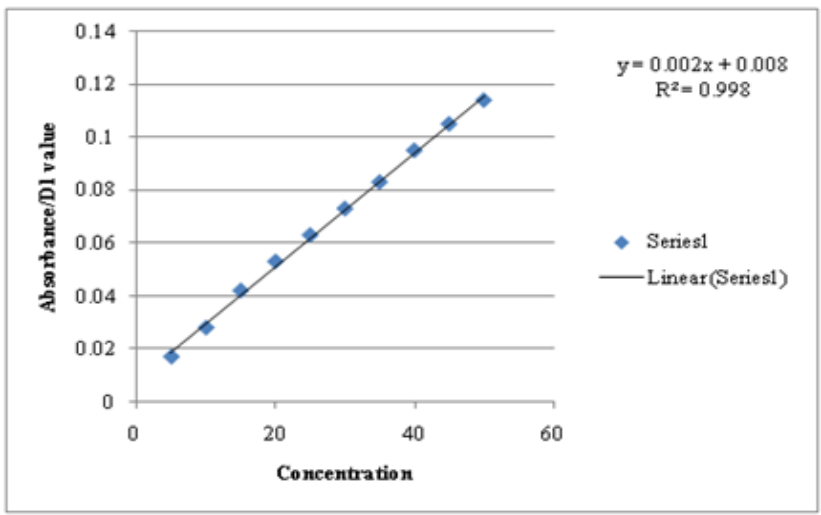

Figure 3: Linearity and range selection of abafungin by $1^{\text {st }}$ order derivative spectroscopy.

$\mathrm{mL}$ was kept at normal conditions. Both solutions were heated on a boiling water bath to remove the excess of hydrogen peroxide. After $15 \mathrm{~min}$, dilution made to achieve $30 \mu \mathrm{g} / \mathrm{mL}$ and analyzed.

\section{Photolytic Degradation}

$30 \mu \mathrm{g} / \mathrm{mL}$ samples were prepared in 5 sets and kept in the UV chamber for $154 \mathrm{hr} / 6$ days $(1.2$ million lux hours). After 6 days sample was analyzed as per the protocol.

\section{RESULTS}

The presented method was validated and with reference to the experimentation and the statistical analysis 
showed fairly agreeable results. Transcutol was deployed as the solved owing to the poor solubility of the drug and the chosen detection wavelength was $242 \mathrm{~nm}$. The drug obeyed the Beer's Law in the range of $5-50 \mu \mathrm{g} /$ $\mathrm{mL}$ with a correlation coefficient of 0.998 . The recovery studies/accuracy of the method were determined from the slope and intercept of the calibration curve. The $\%$ recovery at three levels of concentration was $100.66 \%$ to $107.6 \%$ with $\%$ RSD of 0.680 . The recovery range is well as considering the levels. The $\%$ RSD of interday and intraday precision was 0.950 and 0.341 respectively. $\%$ RSD for ruggedness was found to be $1.28 \%$.

The $\mathrm{pH}$ degradation of active pharmaceutical ingredients was found to be less at 4-7 $\mathrm{pH}$. This shows that the drug is stable in the range of $\mathrm{pH} 4-7$. Stress degradation by hydrolysis under alkaline condition was found to be $7.57 \%$ at $60 \mathrm{~min}$ and $9.63 \%$ for $90 \mathrm{~min}$ for API and 8.53 $\%$ at $60 \mathrm{~min}$ and $10.69 \%$ at $90 \mathrm{~min}$ for formulation. The amount of degradation in alkaline hydrolysis is not very severe and the drug has is $90 \%$ of its content.

Stress degradation under acidic condition by using $3 \mathrm{~N}$ $\mathrm{HCl}$ was executed for which the degradation was found to be $13.72 \%$ for $60 \mathrm{~min}$ and $2.44 \%$ for $90 \mathrm{~min}$ for API. The results depict the stability of Abafungin in the acidic condition that was within the acceptability range. For formulation, the similar study of acidic degradation depicted degradation of $14.55 \%$ at $60 \mathrm{~min}$ and $19.56 \%$ at $90 \mathrm{~min}$.

Dry heat-induced degradation was performed at $70^{\circ} \mathrm{C}$ for $48 \mathrm{hr}$ was found to be $5.36 \%$ for API and $6.32 \%$ for formulation. Hereby the drug and formulation were found to be stable at $70^{\circ} \mathrm{C}$ for three days.

The oxidative degradation was done by using hydrogen peroxide for $15 \mathrm{~min}$. API degradation was found to be $24.65 \%$ and formulation degradation was $23.85 \%$. The drug and the formulation showed some amount of degradation in the oxidative medium. Photolytic degradation was $1.36 \%$ for API and for the formulation it was $1.69 \%$. The degradation of the drug in the presence of light was very less and the drug was found to be most stable in the presence of light.

All the validation parameters as discussed here show a promising approach towards the proposed UV spectrophotometric that is found to be simple, rapid, accurate, precise, selective, economical, reproducible and above all novel.

\section{DISCUSSION AND CONCLUSION}

Abafungin is a broad-spectrum topical antimycotic drug belonging to the class of guanidine's. There is an incessant use of abafungin in the pharmaceutical market. Despite this, there is no reported UV Visible spectrophotometric method for the estimation of Abafungin due to the setback of its solubility in a common solvent. Hence, the stab has been taken to develop a simple, sensitive and economical UV spectroscopic method for the analysis of Abafungin in pure and drug formulation that was found to be reliable and accurate. The development of the stabilityindicating method and the forced degradation studies showed the stability of Abafungin under the performed experimental conditions.

\section{ACKNOWLEDGEMENT}

The authors are thankful to the Columbia Institute of Pharmacy for providing the vital facilities for carrying out the research work. The authors are also grateful to the Department of Science and Technology (DSTFIST) Letter no-SR/FST/COLLEGE/2018/418, New Delhi for providing financial assistance.

\section{CONFLICT OF INTEREST}

Authors declare that there is no conflict of interest.

\section{ABBREVIATIONS}

ICH: International Council for Harmonization; API: Active pharmaceutical ingredient; RSD: Relative standard deviation; SIM: Stability indicating method; LOD: Limit of Detection; LOQ: Limit of Quantification; Nm: namometer; $\mathrm{mg} / \mathrm{mL}$ : milligram per milliliter; Hrs: hours.

\section{REFERENCES}

1. Anonymes, International Conference on Harmonization. Draft Revised Guidance on Validation of Analytical procedures: Text and Methodology, Federal Register Q2 (R1). 2005.

2. Anonymes, International Conference on Harmonization. Draft Revised Guidance on Impurities in New Drug Substances. Federal Register Q3A(R). 2000;65(140):45085.

3. Anonymes, International Conference on Harmonization. (Draft Revised Guidance on Impurities in New Drug Products. Federal Register Q3B(R). 2000;65(139):44791.

4. Anonymes, International Conference on Harmonization. Impurities, Q3C Guidelines for Residual Solvents, Q3C. Federal Register. 1997;62(247):67377.

5. Anonymes, International Conference on Harmonization, S2(R1) Guidance on Genotoxicity Testing and Data Interpretation For Pharmaceuticals Intended For Human Use. 2011

6. Sharma D, Singh R, Garg R. Development and validation of stability indicating UV spectro-photometric method for the estimation of benzydamine hydrochloride in bulk and in pharmaceutical dosage form: A novel analytical technique for conducting in-vitro quality control tests. International Journal of Pharmaceutical Sciences and Research. 2017;9(2):678-86.

7. Dubey S. A Stability Indicating First Order Derivative Spectroscopic Method Development and Validation for Estimation of Pioglitazone. International Journal of Pharmatech Research. 2014;6(2):468-75. 
8. Sonawane S, Jadhav S, Rahade P, Chhajed S, Kshirsagar S. Development and Validation of Stability-Indicating Method for Estimation of Chlorthalidone in Bulk and Tablets with the Use of Experimental Design in Forced Degradation Experiments. Scientifica. 2016;4286482.

9. Warad TA, Todkar VB, Gholve SB, Bhusnure OG, Thonte SS, Thakare VM. UV Spectrophotometric Stability Indicating Method Development and Validation for the Determination of Tenoxicamin Bulk and Dosage Form. Int J Pharm Sci Rev Res. 2017;45(1):74-7.

10. Blessy MR, Patel RD, Prajapati PN, Agrawal YK. Development of forced degradation and stability indicating studies of drugs: A review. J Pharm Anal. 2014;4(3):159-65

11. Dubey. S, Shukla SS. A validated method development for estimation of Simvastatin by First Order Derivative Spectroscopy. Indian Drugs. 2014;51(11):24-7.
12. Borelli $\mathrm{C}$, Schaller M, Niewerth $\mathrm{M}$, Nocker $\mathrm{K}$, Baasner B, Berg D, et al. Modes of action of the new arylguanidine abafungin beyond interference with ergosterol biosynthesis and in vitro activity against medically important fungi. Chemotherapy. 2008;54(4):245-59.

13. Lv QZ, Yan L, Jiang YY. The synthesis, regulation and functions of sterols in Candida albicans: Well-known but still lots to learn. Virulence. 2016;7(6):64959. doi:10.1080/21505594.2016.1188236

14. Ganem-Quintanar A, Lafforgue C, Falson-Rieg F, Buri P. Evaluation of the transepidermal permeation of diethylene glycol monoethyl ether and skin water loss. Int J Pharm. 1997;147(2):165-71.

15. Osborne DW. Diethylene glycol monoethyl ether: An emerging solvent in topical dermatology products. J Cosmet Dermatol. 2011;10(4):324-9.

\section{PICTORIAL ABSTRACT}

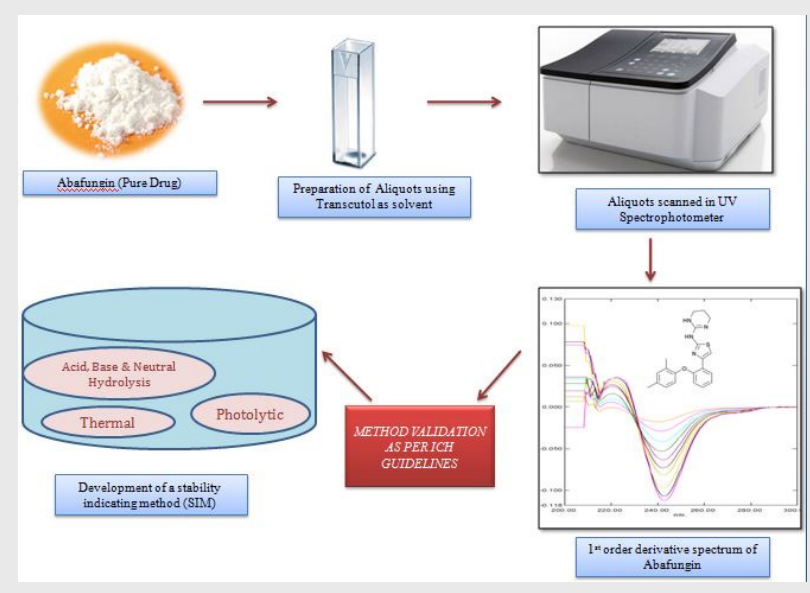

\section{SUMMARY}

A novel stability indicating method by UV spectrophotometry for a topical antimycotic drug abafungin was developed and validated for its estimation in pharmaceutical dosage form. There isn't any single reported method for abafungin through UV which is the novelty of present work. In the presented work, UV spectrophotometric determination was done with $1^{\text {st }}$ order derivative graph at a detection wavelength $242 \mathrm{~nm}$ using diethylene glycol mono ether (transcutol) as solvent. The method was developed and validated with respect to linearity, accuracy, precision, ruggedness, robustness and sensitivity as per the $\mathrm{ICH}$ guidelines. Forced degradation studies were performed relating to acidic, basic, neutral hydrolysis, $\mathrm{pH}$ degradation, oxidative degradation, thermal degradation and photolytic degradation for the analyzing the stressed samples according to the proposed method. For all the validation parameters the percentage relative standard deviation was below $2 \%$. Assay of the drug was established with the marketed formulation of Abafungin to determine the applicability of the method. The range for abafungin for its linearity according to the Beer's lamberts law was from 5-50 $\mu \mathrm{g} / \mathrm{mL}$ with 0.998 as $R^{2}$ value. The forced degradation study didn't show any significant change and recovery laid between 100.66 to $107.6 \%$. The present stability indicating method is found to be simple rapid, novel, accurate, precise and economical that can be used in the routine quality control analysis of abafungin in solid and finished drug products.

\section{About Authors}

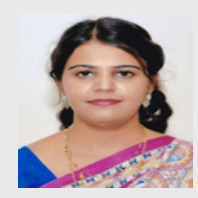

Ms. Swati Pandey gained her post graduate studies from the Chhattisgarh Swami Vivekananda Technical University (CSVTU), Bhilai, Chhattisgarh and Undergraduate from Guru Ghasidas Central University, Bilaspur bagging gold medals in both B. Pharm and M. Pharm. Presently, she is a Ph.D Research Scholar at the Columbia Institute of Pharmacy. She has 7 years of research and academic experience. Her research area of interest includes Pharmaceutical analysis; Impurity profiling; Chromatographic and Spectroscopic techniques. She has 10 publications to her credit in various journals of international and national repute. She has received best oral Presentation award at APTI Central Zone National Seminar (APTI Women Forum) organized by University Institute of Pharmacy, Pt. Ravishankar Shukla University, Raipur, Chhattisgarh, India. She is a life member of IPA. 


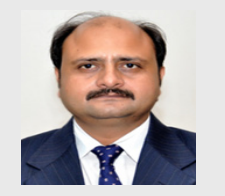

Dr. Ravindra Kumar Pandey gained his Ph.D from the University Institute of Pharmacy, Pt. Ravi Shankar Shukla University. Presently, he is a Professor at the Columbia Institute of Pharmacy. He is having more than 17 years of industrial and academic experience. His research area includes Pharmacognosy, Phytomedicine and Phytochemistry. He has more than 65 publications to his credit in reputed journals. He has authored three books, "Inflammation: Natural Resources and Its Applications" in Series: Springer Briefs in Immunology and "Finger Printing Analysis and Quality Control Methods of Herbal Medicines" in CRC Press Taylor and Francis Group, United Kingdom and "Insight on Genotoxicity" in CRC Press Taylor and Francis Group, United Kingdom. He has organized many National level seminars, workshops. He is the Co-ordinator of DST- FIST Grant (Fund for Improvement in Science and Technology Infrastructure) by Department of Science and Technology, Government of India. He has written three book chapters in reputed publishing houses. He is a life member of APTI and IPA.

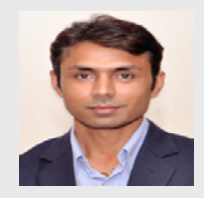

Dr. Shiv Shankar Shukla gained his Ph.D from the University Institute of Pharmacy, Pt. Ravi Shankar Shukla University. Presently, he is a Professor at the Columbia Institute of Pharmacy. $\mathrm{He}$ is having more than 15 years of academic and research experience. He has more than 70 publications to his credit in journals of national and international repute. His thrust area is Method development, Chemical fingerprinting and Pharmaceutical analysis. He has authored three books, "Inflammation: Natural Resources and Its Applications" in Series: Springer Briefs in Immunology and "Finger Printing Analysis and Quality Control Methods of Herbal Medicines" in CRC Press Taylor and Francis Group, United Kingdom and "Insight on Genotoxicity" in CRC Press Taylor and Francis Group, United Kingdom. He has written book chapters published in books from reputed publishing houses. He is the Co-co-ordinator of DST- FIST Grant (Fund for Improvement in Science and Technology Infrastructure) by Department of Science and Technology, Government of India. $\mathrm{He}$ is recipient of " $7^{\text {th }}$ Young Scientist of Chhattisgarh" in 2009 from Chhattisgarh Council of Science and Technology under the discipline of Medical Science and Pharmaceutical Science. He has received "Dr. P. D. Sethi Annual Award" for the best paper in 2010 and Best Oral Paper award in International Conference" in 2nd International Conference on Fostering Interdisciplinary Research in Health Sciences (ICFIRHS) 2019 held at AIMST University, Malaysia, 08100 Bedong, Kedah Darul Aman, Malaysia. He is a life member of APTI and IPA.

Cite this article: Pandey S, Pandey R, Shukla SS. Appliance of the ICH Guidelines: Forced Degradation Studies on Abafungin and Development of Validated Stability Indicating Method by $1^{\text {st }}$ Order Derivative Spectroscopy. Indian $\mathrm{J}$ of Pharmaceutical Education and Research. 2021;55(1):249-55. 